\title{
Deciphering $\beta$-tubulin gene of carbendazim resistant Fusarium solani isolate and its comparison with other Fusarium species
}

Bejoysekhar Datta ( $\sim$ bsd.mycologylab@gmail.com )

University of Kalyani https://orcid.org/0000-0002-3053-7744

Mrinmay Tarafder

University of Kalyani

\section{Research Article}

Keywords: Fusarium solani, Carbendazim resistance, $\beta$-tubulin gene, Phylogenetic analysis, Homology modeling, Molecular docking

Posted Date: February 15th, 2022

DOl: https://doi.org/10.21203/rs.3.rs-1345959/v1

License: (c) (i) This work is licensed under a Creative Commons Attribution 4.0 International License.

Read Full License 


\section{Abstract}

Carbendazim resistance in phytopathogenic Fusarium species is being an immense problem in agricultural practices. Carbendazim exerts fungicidal activity through preventing cell division of target fungi and by binding to $\beta$-tubulin, a major component of microtubule. Several point mutations in the $\beta$ tubulin gene contribute to carbendazim resistance. A full-length (1619 bp) $\beta$-tubulin gene has been cloned and sequenced from a carbendazim resistant (SF0301) and a sensitive (SF0104) isolates of $F$. solani isolated from agricultural fields of Murshidabad $\left(24.23^{\circ} \mathrm{N}, 88.25^{\circ} \mathrm{E}\right)$, West Bengal, India. The phylogenetic position of the isolates was confirmed using ITS and $\beta$-tubulin gene sequences. The $\beta$-tubulin based phylogenetic tree revealed nine species complexes among Fusarium species with available data and separated members of both $F$. solani species complex and $F$. fujikuroi species complex into three clades. The $\beta$-tubulin gene of $F$. solani isolates was organized into five exons and four introns. The intron positions were conserved, but their lengths were shortest among the Fusarium species. The $\beta$-tubulin gene encoded a 446 amino acid protein with a calculated molecular mass $49.834 \mathrm{KD}$, extinction coefficient $41640 \mathrm{M}^{-1} \mathrm{~cm}^{-1}$ and an estimated isoelectric point of 4.64. Amino acid sequence comparison between the resistant and the sensitive isolates revealed that they were all identical, indicating that the mechanism of carbendazim resistance in $F$. solani SF0301 was not due to point mutation in $\beta$-tubulin gene. Homology model of $\beta$-tubulin of $F$. solani isolates was prepared and compared with that of other Fusarium species. The binding sites for GDP, carbendazim and a-tubulin were identified through molecular docking.

\section{Introduction}

$\beta$-tubulin is the key component of the microtubule wherein it is assembled with a-tubulin as heterodimer in head-to-tail manner and involved in many cellular activities, such as cell division, ciliar or flagellar motility, and intracellular transport in eukaryotic organisms (Zhao et al. 2014). This protein is also the target for benzimidazole fungicides such as carbendazim, that are used as foliar spray, seed treatment and post-harvest application to control many plant pathogenic fungi. Through binding at specific site(s) of $\beta$-tubulin they could inhibit cell division in target fungi. In most of the phytopathogenic fungi, resistance against the fungicide is associated with single point mutation at several target sites in the $\beta$ tubulin gene, which results in altered amino acid sequences and change in carbendazim-binding site (Ma and Michailides 2005). This causes a reduction in the affinity of the $\beta$-tubulin for the fungicide, without interfering with normal biological function of $\beta$-tubulin in the fungus. Sometimes a wide range of carbendazim-resistance could be found instead of carrying different mutations at similar amino acid residue and different substitutions at the same codon can exhibit distinct level of resistance (Albertini et al. 1999).

Tertiary structure of any protein provides an important insight into the molecular mechanism of its function, which forms the basis for intending various approaches for structure-based drug designing or altering its structure by site-directed mutagenesis. X-Ray crystallography and NMR are no doubt advance techniques to provide high definition structure of protein, but the disadvantages are that these techniques 
are often prolonged, costly and require large quantity of purified protein. Homology based modeling of protein is an competent computational tool that can be used for predicting the structure of unknown protein based on previously resolved three-dimensional structure of other associates of the same relative having similar folds and/or function. To date, there are hardly any studies on structure-function relationship of $\beta$-tubulin of Fusarium solani exhibiting carbendazim resistance and in particular there is no study on structural properties of $\beta$-tubulin of $F$. solani. Hence, in order to understand their functionality and role in carbendazim resistance, it is imperative to understand molecular structure of the protein.

More than 300 phylospecies (i.e., phylogenetically distinct species) within the monophyletic genus Fusarium are distributed into 23 evolutionary lineages referred to as species complexes (Geiser et al. 2020; O'Donnell et al. 2020). Fusarium solani species complex (FSSC) is one of such lineage which evolved early and contains at least 60 phylogenetically distinct species (Schroers et al. 2016). On the basis of molecular phylogenetic relationships among isolates, O'Donnell (2000) identified three major clades of FSSC. The Clade 1 consisted of New Zealand isolates such as F. illudens which was originally isolated from Metrosideros species. The Clade 2 comprised the South American isolates representing soybean SDS (sudden death syndrome) and bean root rot pathogens, such as F. brasiliense etc. The Clade 3 encompassed all of the isolates formerly characterized as Nectria haematococca and some other species, now clustered as ' $F$. solani' with different formae speciales based on host specificity. In addition, Asian isolates, such as F. ambrosium, African isolates F. neocosmosporiellum and a few South American isolates were included in Clade 3. The members of $F$. solani (Mart.) Sacc. are ubiquitous pathogens of many agriculturally important crops (Coleman 2016). At least 111 plant species from 87 genera are commonly infected by the pathogen (Kolattukudy and Gamble 1995). They cause rot in root and stem, wilt, and damping off in vegetables and legumes, and canker and dieback disease in tropical trees (Leslie and Summerell 2008). They are also responsible for post-harvest decay of many succulent fruits and vegetables. Some strains are associated with human infections. Over 70 Fusarium species have been reported to cause human infections, one-third of them are the members of FSSC which are approximately two-thirds of all the reported Fusarium infections (O’Donnell et al. 2020).

Previously, carbendazim resistant $F$. solani isolates (SF0204, SF0301 and SF1303) which could grow in $100 \mu \mathrm{g} / \mathrm{mL}$ carbendazim and a sensitive isolate (SF0104) which failed to grow in $100 \mu \mathrm{g} / \mathrm{mL}$ carbendazim have been identified from our laboratory (Tarafder et al. 2019). In this study, we have identified the phylogenetic position of the $F$. solani isolates SF0104 and SF0301 based on ITS sequence and reported for the first time, cloning and sequencing of the full-length of $\beta$-tubulin gene, that have been analyzed to detect any mutation responsible for the carbendazim resistance and to compare their nucleotide and amino acid sequences with other Fusarium species and the $\beta$-tubulin gene was used to construct a phylogenetic tree of Fusarium species. Furthermore, we have predicted the three-dimensional structure of the $\beta$-tubulin by homology modeling and the binding sites of GDP, carbendazim and a-tubulin were identified through molecular docking.

\section{Materials And Methods}




\subsection{Fungal isolates}

A number of Fusarium solani isolates were isolated from agricultural fields of Murshidabad $\left(24.23^{\circ} \mathrm{N}\right.$, $88.25^{\circ} \mathrm{E}$ ), West Bengal, India, identified based on morphological characterization and rRNA gene sequencing and their carbendazim sensitivity was studied (Tarafder et al., 2019). Among these, F. solani SF0104 was considered as carbendazim sensitive as it showed only $6.7 \%$ growth in $10 \mu \mathrm{g} / \mathrm{mL}$ carbendazim and failed to grow in $100 \mu \mathrm{g} / \mathrm{mL}$ carbendazim with $\mathrm{ED}_{50}$ value $0.49 \mu \mathrm{g} / \mathrm{mL}$. By contrast, $F$. solani SF0301 was carbendazim resistant and could grow in $100 \mu \mathrm{g} / \mathrm{mL}$ carbendazim with $\mathrm{ED}_{50}$ value $0.98 \mu \mathrm{g} / \mathrm{mL}$. The pure cultures of the isolates were maintained on potato dextrose agar (PDA) medium at the Mycology and Plant Pathology Research laboratory, Department of Botany, University of Kalyani, India.

\subsection{Preparation of phylogenetic tree of FSSC based on ITS sequence}

Genomic DNA was extracted from fresh mycelia using the DNeasy kit (Qiagen, Germany) according to the manufacturer's instruction. The ITS (internal transcribed spacer) of rDNA regions were amplified using ITS5 (F) [5'-GGAAGTAAAAGTCGTAACAAGG-3'] and ITS4 (R) 5'-TCCTCCGCTTATTGATATGC-3'] (Dutta et al. 2018). ITS sequences of the Fusarium species of FSSC were retrieved from GenBank (https://www.ncbi.nlm.nih.gov/genbank) and Al-Hatmi et al. (2018), and used for preparation of phylogenetic tree with MEGA X software (Kumar et al. 2018). The genetic relationships were investigated by applying Neighbour-Join and BioNJ algorithms to a matrix of pairwise distances estimated using the Maximum Composite Likelihood (MCL) approach, and then selecting the topology with superior log likelihood value. The tree was drawn to scale, with branch lengths measured in the number of substitutions per site. The analysis involved 44 nucleotide sequences with a total of 1189 positions in the final dataset. The confidence of the branches was determined with bootstrap analysis in 1000 samplings.

\subsection{Cloning, sequencing and analysis of $\beta$-tubulin gene}

Forward primers $\beta$ OD F (5'-AACATGCGTGAGATTGTAAG-3') was designed from partial $\beta$-tubulin gene sequence of $F$. solani (Accession No. KF255996) and according to O'Donnell and Cigelnik (1997). The reverse primer $\beta$ Ex 5 R (5'-TTACTCCTCGCCCTCAGGG-3') was designed from sequence alignment of a number of Fusarium species whose full sequences were available in database

(https://www.ncbi.nlm.nih.gov/genbank). The start codon and termination codon in the primers are underlined. PCR amplification was performed using Perkin-Elmer PCR system in a $50 \mu \mathrm{L}$ reaction mixture containing $5 \mu \mathrm{L}$ of $10 X$ PCR buffer, $25 \mathrm{mM} \mathrm{MgCl}_{2}, 10 \mathrm{mM}$ dNTPs, $500 \mathrm{nM}$ each primer, $1 \mathrm{U}$ Taq polymerase (Thermo Scientific ${ }^{\mathrm{TM}}$ ), and $100 \mathrm{ng}$ genomic DNA. The thermal programme used for PCR was as follows: a initial denaturation of $5 \mathrm{~min}$ at $95^{\circ} \mathrm{C}$, followed by 35 cycle of denaturation for $30 \mathrm{sec}$ at $94^{\circ} \mathrm{C}$, annealing for $45 \mathrm{sec}$ at $57^{\circ} \mathrm{C}$, and extension at $72^{\circ} \mathrm{C}$ for $2 \mathrm{~min}$, followed by a final extension for 10 min at $72^{\circ} \mathrm{C}$. PCR products were purified with a gel purification kit (Qiagen, Germany), directly ligated into the PGEM-T Easy vector (Promega, USA) and sequenced with the vector primers and internal primers 
using Automated DNA Sequencer (ABI 3500 Genetic Analyzer) (Perkin-Elmer, Applied Biosystem, Inc.) at the S. N. Bose Innovation Centre with Central Instrumentation Laboratory, University of Kalyani. The $\beta$ tubulin sequences of both the isolates were submitted to the GenBank (https://www.ncbi.nlm.nih.gov/genbank) and homology search was carried out using nucleotide BLAST and Fusarium MLST (http://fusarium.mycobank.org). Number, position and size of coding and noncoding region were identified through comparison with other sequences.

\subsection{Comparison of $\beta$-tubulin nucleotide sequence and phylogenetic analysis}

The $\beta$-tubulin sequences of both the isolates SF104 and SF301 were compared with almost full-length $\beta$ tubulin sequences of other Fusarium species which were available in GenBank database (https://www.ncbi.nlm.nih.gov/genbank). The alignment was made by CLUSTAL W (Thompson et al. 1994) using the Blosum matrix and standard default parameters and MEGA X software was used to construct a phylogenetic tree using 56 nucleotide sequences (Kumar et al. 2018).

\subsection{Alignment of $\beta$-tubulin amino acid sequence}

The DNA sequences from the putative coding region were translated into amino acid sequences with the standard code using ExPASy-Translate tool (https://web.expasy.org/translate). The G + C content of coding region, molecular mass, extinction coefficient and isoelectric point of the protein was calculated using web based tools (www.biologicscope.com; www.aatbio.com; www.isoelectric.org). To detect any mutation the deduced amino acid sequences of the resistant and sensitive isolates were aligned and compared. The deduced amino acid sequences of the $F$. solani isolates were compared with $\beta$-tubulin sequences of other Fusarium species through alignment by CLUSTAL W (Thompson et al. 1994) using MEGA X (Kumar et al. 2018).

\subsection{Homology modeling of $\beta$-tubulin}

Homology model of $\beta$-tubulin of $F$. solani isolates and other Fusarium species were carried out using the Swiss-Model programme (https://swissmodel.expasy.org) based on the crystal structure of Bos taurus (PDB code: 404 I of chain D). There were no experimental three-dimensional structures available in PDB for $\beta$-tubulin of $F$. solani. The modeling data were then visualized and analyzed by BIOVIA Discovery Studio Visualizer. The secondary structure of the protein was developed in POLYWIEW-2D (http://polyview.cchmc.org/) (Porollo et al. 2004) and was compared with other Fusarium species.

\subsection{Validation of the model}

The backbone conformation of the modeled structure of $\beta$-tubulin of $F$. solani was intended by the analysis of phi $(\Phi)$ and psi $(\psi)$ torsion angles using Ramachandran plot server (https://zlab.umassmed.edu/bu/rama/ and http://vadar.wishartlab.com/), as resolved by Ramachandran plot statistics. The model was further scrutinized by ProSA (Wiederstein and Sippl 2007) and QMEAN (Benkert et al. 2009). ProSA was used to exhibit the Z-score and energy plots. VADAR 
(http://vadar.wishartlab.com/) was used to calculate the volume area dihedral angle for fractional accessible surface area.

\subsection{Identification of nucleotide binding site(s)}

The nucleotide binding sites within the $\beta$-tubulin was identified using a topological approach. To recognize the nucleotide binding site of PDB file of the modeled $\beta$-tubulin we used software BIOVIA Discovery Studio v21.1.0 using ligand interaction menu.

\subsection{Molecular docking}

To recognize potential binding sites and the binding affinities of carbendazim (PubChem ID: 25429) for $\beta$ tubulin, web-based SwissDock program (www.swissdock.ch/docking) was used to perform automated molecular docking. The blind docking was performed using default parameters, with no region of interest defined. Docking results were visualized using UCSF Chimera v1.13.1 software and BIOVIA Discovery Studio v21.1.0.

To locate a consensus protein-protein binding conformation of a-tubulin and $\beta$-tubilin complex two different docking servers, viz., HADDOCK (High Ambiguity Driven protein-protein DOCKing) (Dominguez et al. 2003; de Vries et al. 2010) and ClusPro (Kozakov et al. 2017; Vajda et al. 2017) were used. The webbased docking tool ClusPro uses the rigid body docking method with the help of PIPER. In PIPER ligands were allowed to move while the conformation of the receptor was kept fixed. Top clusters were ranked with their representative centers on energy scoring functions. The best docked complex was chosen which would comply with the amino acid residues present in the binding interface. We also used HADDOCK web-based server for docking purpose. Rigid body docking server HADDOCK also followed the same steps as in ClusPro. The interfaces of all docked complexes were calculated using PISA server (www.ebi.ac.uk/pdbe/pisa/).

\subsection{Superposition of three-dimensional protein}

The constructed tertiary structure of F. solani was compared with that of other Fusarium species through superimposition in UCSF Chimera (https://www.rbvi.ucsf.edu/chimera) (Pettersen et al. 2004). Using webbased program SuperPose Version 1.0 (http://superpose.wishartlab.com/) the three-dimensional protein of F. solani SF0301 was superimposed with that of F. oxysporum f.sp. cubense. During the superimposition, the following parameters were deposited. To look for sub-domain matches and mismatches (e.g. hinge regions) for pair-wise sequence, the identities were considered above $80 \%$. To identify as 'similar' aligned alpha-carbon atoms with RMSD (root-mean-square deviation) of atomic positions less than $2.0 \AA$ were used as similarity cut off value. To identify as 'dissimilar' aligned alphacarbon atoms with RMSDs greater than $3.0 \AA$ A were used as dissimilarity cutoff value. To set the dissimilar sub-domain, the minimum number of contiguous alpha-carbon atoms with RMSDs above the dissimilarity cutoff (above) required to be considered a 'dissimilar' sub-domain was 7 atoms.

\section{Results}




\subsection{ITS sequence based phylogeny of FSSC members}

The phylogenetic analysis based on ITS sequence separated three major clades of the FSSC members and the F. solani isolates SF104 and SF301 aggregated into the members belonging to Clade 3 (Fig. 1). F. solani SF104 was placed at the same branch with the Indian isolate $F$. ambrosium (FSSC19) and the Slovenian isolate Fusarium sp. (FSSC44), whereas F. solani SF301 was with the Italian isolate $F$. solani (FSSC5).

\subsection{Molecular characterization of $\beta$-tubulin gene}

Using the primer pair $\beta O D F$ and $\beta E x 5 \mathrm{R}$, an approximately $1.6 \mathrm{~kb}$ DNA fragment was amplified from both the $F$. solani isolates. Nucleotide BLAST of the DNA sequences revealed that $98 \%$ identical with partial $\beta$ tubulin genes of different $F$. solani strains/isolates: WNQ3 (GenBank accession no. MK441724), FJBX181 (MN295050), FJBX18-2 (MN295051), and FJBX18-3 (MN295052); 97 \% identical with CMFS007 (KU983876), MICMW-30.1 (KX912242), PaR-1 (MN692927), PaR-2 (MN692928), PaR-3 (MN692929), and F. solani strain causing root rot and stem canker on storage roots of sweet pea in China (KF255996); $96 \%$ identical with FS-01403 (KJ572782). Based on Fusarium MLST identification, the nucleotide sequences showed highest similarity (97.12 \%) with partial sequence (1333 bp) of $\beta$-tubulin gene of $F$. solani species complex NRRL 46706. The $\beta$-tubulin gene sequences of $F$. solani SF0104 and SF0301 were deposited in GenBank under accession numbers MZ409524 and MK900720, respectively.

By comparison with other fungi it was inferred that the full length (1619 bp) $\beta$-tubulin gene of both the $F$. solani isolates was organized into five exons and four introns (Fig. 3A). The intron positions were conserved and occurred after the codons for amino acids 5, 12, 54 and 316, but they varied in their lengths. All introns contained $5^{\prime}$ and $3^{\prime}$ consensus splice junctions similar to those in $\beta$-tubulin genes of other fungi that conformed to the GT-AG rule. The $\mathrm{G}+\mathrm{C}$ content of the coding region was calculated as $58.61 \%$. Both the $\beta$-tubulin genes encoded a 446 amino acid protein, with a calculated molecular mass 49.834 KD, extinction coefficient $41640 \mathrm{M}^{-1} \mathrm{~cm}^{-1}$ and an estimated isoelectric point of 4.64 .

Sequence comparison between the carbendazim resistant and sensitive isolates revealed that they were all identical, indicating that the mechanism of carbendazim resistance in $F$. solani SF0301 was different from other filamentous fungi, where point mutation at different sites on the $\beta$-tubulin gene is responsible for the resistance.

Protein BLAST of the deduced amino acid sequences revealed that $100 \%$ identical with that of $F$. euwallaceae (AMD38824), a member $F$. solani species complex; $99.78 \%$ identical with that of $F$. heterosporum (KAF5674510); $99.55 \%$ with F. oxysporum (XP_018241948), F. verticilloides (XP018748359), F. longipes (RGP77670), F. sacchari (AMD38831), F. denticulatum (KAF5673514) and F. pseudograminearum (XP009254731); 99.33 \% with F. graminearum (PCD17759), F. fujikuroi (AAB18275), F. bulbicola (KAF5979982) and F. commune (AMD38822); 99.1\% with F. babinda (AMD388320) and $F$. poae (AMD38828); and $98.88 \%$ with F. sporotrichioides (RGP75200). 


\subsection{Phylogenetic analysis of Fusarium species based on $\beta$ - tubulin nucleotide sequences}

The phylogenetic analysis of the Fusarium species including $F$. solani based on $\beta$-tubulin gene sequence revealed their position in nine clusters considered as species complexes (Fig. 2). The species complexes are $F$. sambucinum species complex (FSaSC, nine species), $F$. incarnatum-equiseti species complex (FIESC, two species), F. tricinctum species complex (FTSC, two species), F. heterosporum species complex (FHSC, one species), F. fujikuroi species complex (FFSC, 25 species), F. oxysporum species complex (FOSC, four sequences), F. redolens species complex (FRSC, one species), F. decemcellulare species complex (FDSC, one species) and $F$. solani species complex (FSSC, 10 sequences). The phylogenetic tree showed a well-supported relationship ( $99 \%$ MP bootstrap) among the $F$. solani isolates of FSSC under the Clade 3 including our Indian isolates, SF0104 and SF0301. The formation of three clades by FSSC isolates was also confirmed by the analyses based on $\beta$-tubulin sequences. The sister groups FSaSC and FIESC, FTSC and FHSC also showed well-supported lineage with $100 \%$ bootstrap support. $F$. decemcellulare formed lineage from $F$. solani was in accordance with Aoki et al. (2014). The 25 species under the FFSC were phylogenetically placed in three different clades as American, Asian and African the Asian clade was derived from the African clade with 82 \% bootstrap support and American clade from the Asian clade with $100 \%$ bootstrap support.

\subsection{Comparison of $\beta$-tubulin gene of $F$. solani isolates with other Fusarium species}

The $\beta$-tubulin gene of carbendazim resistant $F$. solaniSF0301 was compared with complete $\beta$-tubulin gene of other Fusarium species available in GenBank (Fig. 3B). All Fusarium species including F. solani had $\beta$-tubulin gene with five exons except $F$. graminearum (AY303689), F. praegraminearum (KX260131) and $F$. sambucinum (AF484166) as they lack $4^{\text {th }}$ intron; hence, their total $\beta$-tubulin length became shorter with $1631 \mathrm{bp}, 1629 \mathrm{bp}$ and $1643 \mathrm{bp}$, respectively. Other species also showed variation in total length due to variation of intron length and among these, $1^{\text {st }}$ intron showed maximum variation. The $\beta$ tubulin gene of the $F$. solani isolate was found to be shortest with $1619 \mathrm{bp}$ in length and their introns were shortest among the Fusarium species. Out of the total length of 1619 bp, coding region consisted of 1341 bp and non-coding region with only $278 \mathrm{bp}$ was made up of $1^{\text {st }}, 2^{\text {nd }}, 3^{\text {rd }}$ and $4^{\text {th }}$ introns with $139 \mathrm{bp}, 49$ bp, $44 \mathrm{bp}$ and $46 \mathrm{bp}$, respectively. All the introns in other Fusarium species were larger, thus their $\beta$-tubulin lengths were larger and in the range from $1668 \mathrm{bp}$ in F. redolens (MT011043) to $1684 \mathrm{bp}$ in F. andiyazi (MT011059). The nucleotide length of $2^{\text {nd }}, 3^{\text {rd }}$ and $4^{\text {th }}$ introns were almost similar among the Fusarium species with an average of $58 \mathrm{bp}, 48 \mathrm{bp}$ and $50 \mathrm{bp}$, respectively. However, shorter $2^{\text {nd }}$ intron was found in F. sambucinum (57 bp) and F. solani (49 bp), and larger in F. verticillioides (59 bp). The length of $3^{\text {rd }}$ intron also varied in few species such as, $49 \mathrm{bp}$ in $F$. ramigenum and $F$. napiforme, $47 \mathrm{bp}$ in $F$. redolens and $44 \mathrm{bp}$ in F. solani. The length of $4^{\text {th }}$ intron was 49 bp in F. brevicatenulatum, F. pseudoanthophilum, $F$. 
pseudonygamai, F. verticillioides and F. redolens, whereas in $F$. solani it was $46 \mathrm{bp}$. The variable $1^{\text {st }}$ intron was largest in F. sambucinum (197 bp) and shortest in F. solani (139 bp). Among the total $1341 \mathrm{bp}$ coding region, the length of exons of all Fusarium species was highly conserved and exon 1, 2, 3, 4 and 5 contained 12 bp, 24 bp, 123 bp, 791 bp and 391 bp, respectively. Thus, exon 4 was the largest. However, exon 4 of F. graminearum (AY303689), F. praegraminearum (KX260131) and F. sambucinum (AF484166) were larger than the average length $(791 \mathrm{bp})$ due to lack of $4^{\text {th }}$ intron and contained $1185 \mathrm{bp}, 1182 \mathrm{bp}$ and $1182 \mathrm{bp}$, respectively. The $\beta$-tubulin of all the Fusarium species encoded 446 amino acid protein except $F$. graminearum which encoded 447 amino acid protein. All these data were calculated only from $\beta_{7}$-tubulin nucleotide sequence from those which had two $\beta$-tubulin genes.

\subsection{Comparison of $\beta$-tubulin amino acid of $F$. solani isolates with other Fusarium species}

The most frequent difference of $\beta$-tubulin amino acid sequence of $F$. solani isolates with other Fusarium species was found to be at $381^{\text {st }}$ position with isoleucine (I) in $F$. solani isolates and valine (V) in other (Fig. 4). However, F. avenaceum and $F$. heterosporum also contained isoleucine at $381^{\text {st }}$ position similar to the $F$. solani isolates. But they differed from $F$. solani isolates at $189^{\text {th }}$ position where valine in $F$. solani was changed as isoleucine in these two species. Another difference was identified at $335^{\text {th }}$ position where asparagine $(\mathrm{N})$ in $F$. solani isolates was changed to serine $(\mathrm{S})$ in other Fusarium species. However, this change was not detected in species such as F. oxysporum, F. fujikuroi, F. verticilloides, $F$. decemcellulare, F. avenaceum and $F$. heterosporum. The amino acid proline $(\mathrm{P})$ was only found in $F$. oxysporum f.sp. cubense at $279^{\text {th }}$ position, where as in others it was histidine $(H)$. In addition, a few minor changes were found in different species (Fig. 4).

\subsection{Homology modeling and structural analysis}

To build a tertiary structural model of $\beta$-tubulin, an appropriate template has been searched using SwissModel (https://swissmodel.expasy.org). Of the yielded templates, the crystal structure of Bos taurus (PDB ID: 404I) was found to be the best template with the sequence identity of $83.15 \%$ with the query coverage of $96.64 \%$ and the QMEAN score of the built model was -1.85 . A tertiary model structure of $\beta$ tubulin was again built up by BIOVIA Discovery Studio package using the crystal structure. The threedimensional model of the protein was found to be composed of different secondary structural elements (Fig. 5).

\subsubsection{Proposed secondary structural conformation}

The secondary structure of $\beta$-tubulin of $F$. solani had proposed to contain 21 a-helices, $16 \beta$-strands and several coils (Fig. 5A). The a-helices were formed with the amino acid position from 10-27, 41-44, 47-49, 
71-78, 87-89, 101-105, 108-126, 143-158, 181-195, 204-213, 222-241, 250-257, 276-279, 286-293, 296-298, $305-307,323-336,338-340,372-389,396-399$ and $405-427$. The $\beta$-strands were found with the amino acid position from 4-9, 30, 36, 51-54, 58-61, 63-68, 90-92, 131-138, 163-170, 198-203, 265-271, 299, 310-319, $341,249-354$ and $363-371$. When the constructed secondary structure of $\beta$-tubulin of $F$. solani was compared with that of other species using POLYVIEW-2D, it was observed that all the Fusarium species had identical secondary structural elements. However, F. oxysporum f.sp. cubense contains 20 a-helices due to presence of proline (instead of histidine in other) at $279^{\text {th }}$ position and as proline is a helix breaker, the a-helix formed by ARG276, GLY277, ALA278 and HIS279 in other Fusarium species is absent in F. oxysporum f.sp. cubense (Fig. 5B).

\subsubsection{Model reputation}

The stereo-chemical behavior of the predicted model of $\beta$-tubulin protein of $F$. solani was analyzed through ProSA and QMEAN server's confirmation and evaluated by the Phi/Psi Ramachandran plot inspection. ProSA was used to confirm the three-dimensional model of $\beta$-tubulin protein for potential errors. The program displayed two attributes of the input structure: its Z-score and a plot of its residue energies. The ProSA Z-score of -10.11 indicates the overall model quality of $\beta$-tubulin protein (Fig. 6A). The deviation of total energy of the structure, measured by the Z-score, with respect to an energy distribution obtained from random conformations. The scores were well within the range of scores and indicated a highly reliable structure typically found for proteins of comparable size. The energy plot demonstrated the local model superiority by plotting the knowledge-based energies as function of the amino acid sequence position (Fig. 6B). QMEAN analysis was also employed to evaluate and validate the model. The QMEAN4 score of the model was 0.82 (Fig. 6C) and the Z-score was -1.85 which was close to zero and this confirmed the superior quality of the model. This is because the estimated consistency of the model was projected to be in between 0 and 1 (Table 1). Assessment between regularized QMEAN score (0.82) and protein size in non-redundant set of PDB structure in the plot revealed different set of Zvalues for different parameters such as C-beta interactions $(0.28)$, interactions between all atoms $(0.24)$, solvation (0.85) and torsion (-2.31) (Table 1).

The constructed homology model was also assessed for structural and stereo-chemical competency. A Ramachandran Phi/Psi plot for $\beta$-tubulin (Fig. 6D) showed 97.436 \% highly preferred observations, 1.865 $\%$ preferred observations and $0.699 \%$ questionable observations. The analysis of the predicted structure provided strong evidence that the predicted three-dimensional structure of $\beta$-tubulin was of superior quality.

\subsubsection{Determination of putative nucleotide binding sites}

In order to explore the spatial relationships between nucleotide and $\beta$-tubulin we used a topological approach after homology modeling. The nucleotide-binding domain in $\beta$-tubulin was depicted in Fig. 7A and B. We assumed that the GDP-binding site of $\beta$-tubulin was composed of two components: a 
guanine-binding component and a phosphoryl-binding component. The guanine-binding component was composed of CYS12, GLN15, SER176, GLU181, ASN204, TYR222 and ASN226 and the phosphorylbinding component was composed of GLN11, SER138, GLY141, GLY142 and THR143. The binding pattern and the $\mathrm{H}$-bond formation are according to the Fig. 7A and $\mathrm{B}$ and Table 2.

\subsubsection{Molecular docking to identify carbendazim binding site(s)}

Molecular docking was performed to map the interactions between carbendazim and $\beta$-tubulin and to find out putative binding site(s). The molecular docking of carbendazim and $\beta$-tubulin detected 48 clusters in eight different sites of the protein. The top-score cluster exhibited best "full fitness" and those parameters were calculated by averaging the $30 \%$ most favourable effective energies of a cluster's element and lower free energy than those obtained for other potential binding sites (Grosdidier et al., 2007; Vela-Corcía et al., 2018). The pocket atoms of $\beta$-tubulin for carbendazim binding site were VAL193,

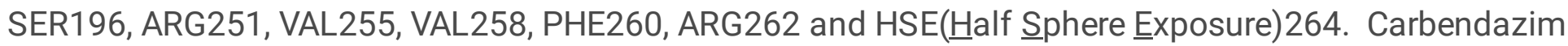
bound with $\beta$-tubulin with different kind of interactive forces such as classical hydrogen bond, nonclassical hydrogen bond, electrostatic interaction (charged) and alkyl hydrophobic interaction. There were a conventional hydrogen bond between MBC:H18 and $\beta$ :PR0261:0; two non-conventional hydrogen bonds between MBC:H16 and $\beta: G L U 194: O, M B C: H 17$ and $\beta: G L U 194: 0 ;$ seven charged-electrostatic interactions between $\beta: A R G 156: H Z 2$ and MBC:C1, $\beta$ :ARG156:HZ2 and MBC:C3, $\beta: G L U 194: C A$ and MBC:C1, $\beta: A S N 195: C A$ and MBC:C1, $\beta: A S P 197: C A$ and MBC:C3, $\beta: P R 0261: C A$ and MBC:C1, $\beta: P R 0261: C A$ and MBC:C3; alkyl hydrophobic interaction between $\beta$ :ALA254 and MBC (Fig. 7C and D). All the putative bonds with their bond distance were in accordance with Table 3 .

\subsubsection{Dimerization of $\alpha$ - and $\beta$-tubulins}

Hetero-dimerization of $a-$ and $\beta$-tubulin subunits was also checked by protein-protein docking. The two monomers were interacted to each other with $\mathrm{H}$-bonds and electrostatic interactions. The $\mathrm{H}$-bonds were formed through salt bridge formation, conventional $\mathrm{H}$-bonds and non-conventional with carbon-hydrogen bond formation. Out of total eleven bonds/interactions, the monomer $\beta$-tubulin contributed six amino acids as $\mathrm{H}$-donor and five amino acids as $\mathrm{H}$-acceptor. The amino acid representatives of $\alpha$ - and $\beta$-tubulin monomers with their actual positions in the peptide chain, the bond distance and bond angles are represented in Table 4 . The $\beta$-tubulin of $F$. solani isolates had sites for the putative beta/alpha domain interface at ASP128, CYS129, ARG162, LYS252, ASN256, ARG331, ASN347, GLN350 and GLY429 (Fig. 7E).

\subsection{Comparison of $\beta$-tubulin tertiary structure}


Homology models of $\beta$-tubulin of all the Fusarium species were constructed and to identify any discrimination with the $F$. solani protein, superimposition was performed. Though few regions in amino acid residues were dissimilar among the species, the tertiary structural superimpositions were nearly identical. This could be due to substitution of the amino acids with the same class of other amino acids. The three-dimensional model of $\beta$-tubulin of $F$. oxysporum f.sp. cubense, however, differed from that of $F$. solani SF0301 and other species (Fig. 8A and B). In $\beta$-tubulin of $F$. oxysporum f.sp. cubense, PRO279 (yellow) strongly refused to form an a-helix and acted as a helix-breaker (Fig. 8D); where as in all other Fusarium species including F. solani, HIS279 (yellow) formed an extra a-helix (Fig. 8C). In Fig. 8C, the schematic diagram of $\beta$-tubulin of $F$. solani SF0301 showed ARG213 (blue) as a component of an a-helix while in F. oxysporum f.sp. cubense (Fig. 8D) ARG213 was not integrated into the a-helix rather it formed loop with its $\mathrm{C}$ terminal amino acid residue.

\section{Discussion}

Geiser et al. (2020) used 19 protein coding genes to study phylogeny of Fusarium species. Among these, they considered rDNA and $\beta$-tubulin genes. In this study, we confirmed phylogenetic position of our $F$. solani isolates isolated from Indian subcontinent based on ITS sequence and $\beta$-tubulin gene sequence (Figs. 1 and 2). Although, $\beta$-tubulin gene sequences of both the isolates were identical, they differed slightly in ITS sequence and was placed apart in the ITS sequence based phylogenetic tree. However, both the ITS and $\beta$-tubulin gene sequence based phylogenetic trees separated the members of the Fusarium solani species complex into three clades and F. solani isolates, SF104 and SF301 were placed in Clade 3.

The $\beta$-tubulin gene has been widely used in fungal phylogenetic analysis because it possesses both variable and highly conserved regions, and it is supposed to have more stability and reliability in the demarcation of Fusarium species as compared with the rRNA gene (Myburg et al. 2002). The $\beta$-tubulin contains 3.5-fold more phylogenetic information than the SSU rRNA gene (Begerow et al. 2004). Unlike rRNA genes, it is non-repetitive and accumulates fewer mutations. Its intron positions are known to be conserved and in this respect an extensive analysis of the introns and their positions are important in phylogenetic studies. When $\beta$-tubulin gene was used as molecular marker for construction of phylogenetic tree, the positions of the Fusarium species within the nine species complexes was almost similar with the phylogenetic analysis of O'Donnell et al. (2013), inferred from a combined gene sequences of RPB1 and RPB2 datasets. Molecular phylogenetic analysis indicated that the genus Fusarium was originated in the middle Cretaceous period approximately 91.3 million years ago. The fragmentation of Gondwanaland during the upper Cretaceous through the Paleocene played a central role in the emergence of clades in several species complexes. The FSSC originated near New Zealand component of Gondwana because isolates collected from this region constituted the basal clade, Clade 1. Clade 2, included isolates of South America, and Clade 3, consisting of the isolates from Asia and Africa were most likely to have emerged later due to the reproductive barrier imposed by fragmentation of the ancient southern hemisphere super continent (Bogale et al. 2009). In FFSC, the emergence of the American clade, together with the Asian clade and African clade was initially recommended by O'Donnell 
et al. (1998) due to the fragmentation of Gondwanaland. Afterward, the same authors reported that the complex emerged more recently (ca. 8.8 million year ago) and that the apparent biogeographic clustering was probably due to long distance dispersal from South America to Africa and then to Asia in the late Miocene (O'Donnell et al. 2013). Distribution of species in three clades of FFSC was in accordance with the Maximum likelihood phylogeny of the FFSC inferred from the combined translation elongation factor 1- $\alpha$ and $\beta$-tubulin gene regions sequence data of Herron et al. (2015). O'Donnell et al. (1998) also grouped the FFSC taxa into the American, African and Asian clades.

In the present study, we characterized organization of $\beta$-tubulin gene of $F$. solani isolates. The gene was organized into five exons of variable length (Fig. 3A). To the best of our knowledge, this was the first report of complete $\beta$-tubulin gene sequence of $F$. solani. The full-length nucleotide sequences were in agreement with partial sequences of various $F$. solani isolates available in database (https://www.ncbi.nlm.nih.gov/genbank). We also observed that $\beta$-tubulin genes of Fusarium species varied significantly in their length and the variation was due to difference of their intron lengths especially the $1 \mathrm{st}$ intron, which was largest among the four introns. However, the number and length of exon among Fusarium species were almost conserved (Fig. 3B). We also compared the deduced amino acid sequence of $\beta$-tubulin of different Fusarium species (Fig. 4) and constructed the secondary and tertiary structure of $\beta$-tubulin protein of $F$. solani through homology modeling and compared the structure with that of other Fusarium species (Fig. 5). The constructed $\beta$-tubulin was scrutinized by ProSA and QMEAN analysis and validated by the analysis of phi $(\Phi)$ and psi $(\psi)$ torsion angles using Ramachandran plot (Fig. 6).

During polymerization of microtubules, tubulin monomer shows GTPase activity and the GTP bound with $\beta$-tubulin is hydrolyzed shortly after being incorporated. Therefore, GDP is predominantly associated in the $\beta$-tubulin subunit near the newly formed plus end (Horio and Murata 2014). A highly conserved glycine-rich sequence, GGGTGAG, has been identified from residues 140 to 146 in the $F$. solani $\beta$-tubulin which formed part of the GDP-14 binding site as reported by Nogales et al. (1998). As similar to other fungi, the $\beta$-tubulin of $F$. solani isolates encoded an N terminal tetrapeptide MREl which was involved in the autoregulation of $\beta$-tubulin expression as detected in mammalian cells (Msiska and Morton 2009).

Carbendazim has been reported to bind at specific position of the $\beta$-tubulin in different fungi (Zhou et al. 2016; Vela-Corcía et al. 2018; Yang et al. 2018; Xu et al. 2019) while, to the best of our knowledge, no evidence has been raised for physical interaction between carbendazim and $\beta$-tubulin in $F$. solani. In this study, the interaction has been demonstrated through molecular docking. Zhou et al. (2016) showed that, in F. graminearum carbendazim inhibited the dimerization of tubulin by binding with the $\beta_{2}$-tubulin; but unable to affect the polymerized tubulin. In our study, we investigated the mystery behind the binding of carbendazim to the monomeric form but not to the polymerized tubulin. The carbendazim binding pocket in $\beta$-tubulin in $F$. solani, consisting of amino acids at the position was close to the $\alpha / \beta$-tubulin subunit interfaces (Fig. 7). Therefore, due to the presence of carbendazim binding pocket inside the $\beta$-tubulin, we can assume that the formation of carbendazim- $\beta$-tubulin complex resulted in conformation change in $\alpha /$ $\beta$-tubulin subunit interfaces followed by losing the ability of these subunits to accept other tubulin 
molecules for further microtubule polymerization. In contrast, polymerized microtubules may have compacted organization that destroyed the accessibility of carbendazim to the $\beta$-tubulin.

Among the naturally occurring amino acids, proline is unique in that its side chain cyclically back to the backbone amide, leaving one of its dihedral angles $(\phi)$ fixed at $-65^{\circ}$ (Richardson and Richardson 1989; MacArthur and Thornton 1991). Proline residue is not often found at the center of secondary structures such as the a-helix and $\beta$-sheet in globular protein due to the structural consequence of this particular arrangement (Chou and Fasman 1978, 1974). When proline is located in the first turn, acting apparently as an N-capping residue, it does occur in an a-helix (Richardson and Richardson 1988). In our study, to compare the secondary structure formed in $\beta$-tubulin among different Fusarium species, homology modeling of the $\beta$-tubulin protein followed by superimposition of each $\beta$-tubulin with the $\beta$-tubulin of $F$. solani was carried out. Algorithms to superimpose protein's three-dimensional structures were applied to identify similarities of protein folds. The coordinates of a protein was superposed so that the backbone lies over the backbone of a reference protein. Distant homologues might not be recognized by their amino acid sequence because the sequences diverge more rapidly in evolution than the three-dimensional structure. The most significant difference was observed at the 279th position in F. oxysporum f.sp. cubense due to presence of proline instead of histidine (Fig. 5). In F. oxysporum f.sp. cubense proline was located in the last turn, acting apparently as a C-capping residue of a-helix and acted as a helix breaker whereas, in others including F. solani HIS279 was a part of a-helix (Fig. 8). Proline is unfavorable to the ahelical conformation for the several reasons. Firstly, due to the absence of an amide proton on an x-Pro ( $x=$ any amino acid residue) bond which participates in helix stabilization during intramolecular hydrogen bonding (Williams and Deber 1991). Secondly, its pyrrolidine ring is too bulky to place steric constraint on the conformation of the earlier residue in the a-helix (Hurley et al. 1992). Finally, proline, being a secondary amide, is comparatively a polar residue that exhibits an enhanced tendency to form strong hydrogen bonds in non-periodic structural motifs such as proline-induced $\beta$-turns (Smith et al. 1980) and $Y$-turns (Deber et al. 1990). Although, no significant differences in protein function were observed in $F$. oxysporum f.sp. cubense because PRO279 was not the interacting residue in both tubulin polymerization as well as carbendazim binding. The other amino acid substitution(s) in different location among the species was not significant for the changes of secondary structure probably due to the substitution by the amino acid of same chemical group.

The main objective of the study was to address the molecular basis of carbendazim resistance of a $F$. solani isolate which could grow in $100 \mu \mathrm{g} / \mathrm{mL}$ carbendazim. Carbendazim resistance develops rapidly in many pathogenic fungi including Fusarium species (Zhang et al. 2016; Avenot et al. 2019; Liu et al. 2020). Resistant isolates can adapt to environmental conditions to become dominant in pathogen populations under selection pressure of the fungicides, and in turn decrease fungicide effectiveness. Similarly isolates typically arise as resistant with a very low natural rate of mutation in a specific gene (Ma and Michailides 2005). In several species of Fusarium, point mutation of nucleotides (underlined) and resulting change of amino acids at various positions of $\beta$-tubulin have been reported:

TYR(TAC)50ASP(AAC), TYR(TAC) 50CYS(TGC), GLN(CAG)134LEU(CTG), PHE(TTT)167TYR(TAT), GLU(GAG)198LYS(AAG), GLU(GAG)198GLN(CAG), GLU(GAG)198ALA(GCG), GLU(GAG)198VAL(GTG), 
PHE(TTC)200TYR(TAC), THR(ACA)351ILE(ATA) (Yan and Dickman 1996; Qiu et al. 2011; Suga et al. 2011; Chen et al. 2014; Petkar et al. 2017; Yang et al. 2018; Xu et al. 2019). In addition, substitutions have also been observed at the position of 6, 165, 235, 240 and 241 in other phytopathogenic fungi (Ma and Michailides 2005). Some fungi contained two $\beta$-tubulin genes and among these, only one was responsible of benzimidazole resistance. However, $F$. solanicontained only one $\beta$-tubulin gene with four copies (Zhao et al., 2014). In this study, $\beta$-tubulin genes of the carbendazim resistant and the sensitive isolates were identical and no point mutations were found in F. solani SF0301 $\beta$-tubulin gene. This might be due to the resistance factor (the ration of $\mathrm{ED}_{50}$ of resistant and sensitive isolates) of $F$. solani SF0301 was very low (2.0) than that of other plant pathogenic fungi (>1000) (Chen et al. 2007). However, this observation suggested that the mechanism of carbendazim resistance in F. solani SF0301 might be due to overproduction of the fungicide target, detoxification of the fungicide by some fungal metabolite, an active efflux or reduced uptake of the fungicide and some unknown mechanisms (Sevastos et al. 2017). In Gibberella pulicaris (= F. sambucinum) the amino acid sequences of the $\beta$-tubulin gene from several thiabendazole- resistant and -sensitive isolates were identical and $\beta$-tubulin gene was not linked to thiabendazole resistance (Kawchuk et al. 2002). In benomyl-resistant Colletotrichum acutatum isolates, putative leucine zipper protein CaBEN1 increased production of the target protein by enhancing $\beta$-tubulin gene (CaTUB1) expression (Nakaune and Nakano 2007). Recently, Vígla`s and Olejníkova (2021) stated that in filamentous fungi the $A B C$ transporters play a key role in antifungal resistance by transporting various xenobiotics, including antifungal compounds. F. graminearum mutants with ABC4 transporters were significantly less tolerant to epoxyconazole and prothioconazole. Additionally, toxin-efflux ATPbinding cassette $(\mathrm{ABC})$ transporters were involved in resistance to benzimidazole fungicides in Aspergillus nidulans (Andrade et al. 2000) and Penicillium digitatum (Nakaune et al. 1998). These reports demonstrated that the resistance to benzimidazole fungicides could be partially due to the membrane transport system for these compounds into the fungal cells. Some mutations in the a-tubulin gene of Saccharomyces cerevisiae increased benzimidazole sensitivity (Richards et al. 2000). Further investigations are warranted in understanding the existence of resistant mechanism of benzimidazole fungicides in F. solani SF301.

\section{Conclusions}

Carbendazim resistant $F$. solani SF0301 did not have any mutation in the $\beta$-tubulin gene. Sequence comparison of the ITS and $\beta$-tubulin gene confirmed the phylogentic placement of the Indian isolates of F. solani within Clade 3 of FSSC. The deduced amino acid sequence showed some variations with $\beta$ tubulin of other Fusarium species. Homology modeling and structural analysis of $\beta$-tubulin of $F$. solani resolved putative nucleotide (GDP) binding site, carbendazim binding site and binding pattern with atubulin.

\section{Declarations}

\section{Acknowledgements}


The work has been supported by the funds received from University of Kalyani and DST-FIST and DSTPURSE programme II, Govt. of India

\section{Disclosure statement}

We declare no conflict of interest

\section{References}

1. Albertini C, Gredt M, Leroux P (1999) Mutations of the $\beta$-tubulin gene associated with different phenotypes of benzimidazole resistance in the cereal eyespot fungi Tapesia yallundae and Tapesia acuformis. Pestic Biochem Physiol 64:17-31. https://doi.org/10.1006/pest.1999.2406

2. Al-Hatmi AMS, Ahmed SA, van Diepeningen, AD, Drogari-Apiranthitou M, Verweij PE, Meis J F, de Hoog G S (2018) Fusarium metavorans sp. nov.: The frequent opportunist "FSSC6." Medical Mycology 56: S144-S152. https://doi.org/10.1093/mmy/myx107

3. Andrade AC, Del Sorbo G, Van Nistelrooy JGM, De Waard MA (2000) The ABC transporter AtrB from Aspergillus nidulans mediates resistance to all major classes of fungicides and some natural toxic compounds. Microbiology 146:1987-1997. https://doi.org/10.1099/00221287-146-8-1987

4. Aoki T, O’Donnell K, Geiser DM (2014) Systematics of key phytopathogenic Fusarium species: Current status and future challenges. J Gen Plant Pathol 80:189-201. https://doi.org/10.1007/s10327-014-0509-3

5. Avenot HF, Morgan DP, Quattrini J, Michailides TJ (2020) Resistance to Thiophanate-Methyl in Botrytis cinerea Isolates from Californian Vineyards and Pistachio and Pomegranate Orchards. Plant Dis 104:1069-1075. https://doi.org/10.1094/PDIS-02-19-0353-RE

6. Begerow D, John B, Oberwinkler F (2004) Evolutionary relationships among $\beta$-tubulin gene sequences of basidiomycetous fungi. Mycol Res 108:1257-1263. https://doi.org/10.1017/S0953756204001066

7. Benkert P, Künzli M, Schwede T (2009) QMEAN server for protein model quality estimation. Nucleic Acids Res 37:510-514. https://doi.org/10.1093/nar/gkp322

8. Bogale M, Steenkamp ET, Wingfield MJ, Wingfield BD (2009) Diverse Fusarium solani isolates colonise agricultural environments in Ethiopia. Eur J Plant Pathol 124: 369-378.

9. Chen C, Wang J, Luo Q, Yuan S, Zhou M (2007) Characterization and fitness of carbendazimresistant strains of Fusarium graminearum (wheat scab). Pest Management Science 63: 1201-1207 . https://doi.org/10.1002/ps.1449

10. Chen Z, Gao T, Liang S, et al (2014) Molecular mechanism of resistance of Fusarium fujikuroi to benzimidazole fungicides. FEMS Microbiol Lett 357:77-84. https://doi.org/10.1111/15746968.12504 
11. Chou PY, Fasman GD (1978) Empirical predictions of protein conformation. Annu Rev Biochem 47:251-276. https://doi.org/10.1146/annurev.bi.47.070178.001343

12. Chou PY, Pasman GD (1974) Conformational Parameters for Amino Acids in Helical, $\beta$-Sheet, and Random Coil Regions Calculated from Proteins. Biochemistry 13:211-222. https://doi.org/10.1021/bi00699a001

13. Coleman JJ (2016) The Fusarium solani species complex: Ubiquitous pathogens of agricultural importance. Mol Plant Pathol 17:146-158. https://doi.org/10.1111/mpp.12289

14. De Vries SJ, Van Dijk M, Bonvin AMJJ (2010) The HADDOCK web server for data-driven biomolecular docking. Nat Protoc 5:883-897. https://doi.org/10.1038/nprot.2010.32

15. Deber CM, Glibowicka M, Woolley GA (1990) Conformations of proline residues in membrane environments. Biopolymers 29:149-157. https://doi.org/10.1002/bip.360290120

16. Dominguez C, Boelens R, Bonvin AMJJ (2003) HADDOCK: A protein-protein docking approach based on biochemical or biophysical information. J Am Chem Soc 125:1731-1737. https://doi.org/10.1021/ja026939x

17. Duke SO, Powles SB (2008) Glyphosate: a once-in-a-century herbicide. Pest Manag. Sci. 63: 11001106. https://doi.org/10.1002/ps.1518

18. Dutta S, Tarafder M, Islam R, Datta B (2018) Biocatalysis and Agricultural Biotechnology Characterization of cellulolytic enzymes of Fusarium soil Isolates. 14:279-285

19. Geiser DM, Al-Hatmi A, Aoki T, et al (2020) Phylogenomic analysis of a $55.1 \mathrm{~kb}$ 19-gene dataset resolves a monophyletic Fusarium that includes the Fusarium solani Species Complex.

Phytopathology ${ }^{\circledR} 1$ 1-64. https://doi.org/10.1094/phyto-08-20-0330-le

20. Grosdidier A, Zoete V, Michielin O, (2007) EADock: docking of small molecules into protein active sites with a multiobjective evolutionary optimization. Proteins 67: 1010-1025. https://doi.org/10.1002/prot.21367.

21. Herron DA, Wingfield MJ, Wingfield BD, et al (2015) Novel taxa in the Fusarium fujikuroi species complex from Pinus spp. Stud Mycol 80:131-150. https://doi.org/10.1016/j.simyco.2014.12.001

22. Horio T, Murata T, Murata T (2014) The role of dynamic instability in microtubule organization. Front Plant Sci 5:1-11. https://doi.org/10.3389/fpls.2014.00511

23. Hurley JH, Mason DA, Matthews BW (1992) Flexible-geometry conformational energy maps for the amino acid residue preceding a proline. Biopolymers 32:1443-1446.

https://doi.org/10.1002/bip.360321104

24. Kawchuk LM, Hutchison LJ, Verhaeghe CA, et al (2002) Isolation of the $\beta$-tubulin gene and characterization of thiabendazole resistance in Gibberella pulicaris. Can J Plant Pathol 24:233-238. https://doi.org/10.1080/07060660309507001

25. Kolattukudy PE, Gamble DL, (1995) Nectria haematococca: pathogenesis and host specificity in plant diseases. In: Kohmoto K, Singh US, Singh RP, (ed.) Pathogenesis and Host specificity in Plant Pathogenic Fungi and Nematodes. Vol 2. Eukaryotes Pergamon; Oxford, pp. 83-102 
26. Kozakov D, Hall DR, Xia B, et al (2017) The ClusPro web server for protein-protein docking. Nat Protoc 12:255-278. https://doi.org/10.1038/nprot.2016.169

27. Kumar S, Stecher G, Li M, et al (2018) MEGA X: Molecular evolutionary genetics analysis across computing platforms. Mol Biol Evol 35:1547-1549. https://doi.org/10.1093/molbev/msy096

28. Leslie JF, Summerell BA (2008) The Fusarium laboratory manual. New York, Wiley

29. Liu S, Liu J, Fu L, et al (2020) Baseline sensitivity of Fusarium graminearum from wheat fields in Henan, China, to metconazole and analysis of cross resistance with carbendazim and phenamacril. J Phytopathol 168:156-161. https://doi.org/10.1111/jph.12874

30. Ma Z, Michailides TJ (2005) Advances in understanding molecular mechanisms of fungicide resistance and molecular detection of resistant genotypes in phytopathogenic fungi. Crop Prot 24:853-863. https://doi.org/10.1016/j.cropro.2005.01.011

31. MacArthur MW, Thornton JM (1991) Influence of proline residues on protein conformation. J Mol Biol 218:397-412. https://doi.org/10.1016/0022-2836(91)90721-H

32. Msiska Z, Morton JB (2009) Isolation and sequence analysis of a beta-tubulin gene from arbuscular mycorrhizal fungi. Mycorrhiza 19:501-513. https://doi.org/10.1007/s00572-009-0248-z

33. Myburg H, Gryzenhout M, Wingfield BD, Wingfield MJ (2002) $\beta$-tubulin and histone H3 gene sequences distinguish Cryphonectria cubensis from South Africa, Asia, and South America. Can J Bot 80:590-596. https://doi.org/10.1139/b02-039

34. Nakaune R, Adachi K, Nawata O, et al (1998) A novel ATP-binding cassette transporter involved in multidrug resistance in the phytopathogenic fungus Penicillium digitatum. Appl Environ Microbiol 64:3983-3988. https://doi.org/10.1128/aem.64.10.3983-3988.1998

35. Nakaune R, Nakano M (2007) Benomyl resistance of Colletotrichum acutatum is caused by enhanced expression of $\beta$-tubulin 1 gene regulated by putative leucine zipper protein CaBEN1. Fungal Genet Biol 44:1324-1335. https://doi.org/10.1016/j.fgb.2007.03.007

36. Nogales E, Downing KH, Amos LA, Lowe J (1998) Tubulin and FtsZ form a distinct family of GTPases. Nat Struct Mol Biol 5:451-458. https://doi.org/10.1038/nsb0698-45

37. O'Donnell K (2000) Molecular phylogeny of the Nectria haematococca-Fusarium solani species complex. Mycologia 92:919-938. https://doi.org/10.1080/00275514.2000.12061237

38. O'Donnell K, Al-Hatmi AMS, Aoki T, et al (2020) No to Neocosmospora: Phylogenomic and Practical Reasons for Continued Inclusion of the Fusarium solani Species Complex in the Genus Fusarium . mSphere 5:. https://doi.org/10.1128/msphere.00810-20

39. O’Donnell K, Cigelnik E (1997) Two Divergent Intragenomic rDNA ITS2 Types within a Monophyletic Lineage of the FungusFusariumAre Nonorthologous. Mol. Phylogenet. Evol. 7: 103-116. https://doi.org/10.1006/mpev.1996.0376

40. O'Donnell K, Rooney AP, Proctor RH, et al (2013) Phylogenetic analyses of RPB1 and RPB2 support a middle Cretaceous origin for a clade comprising all agriculturally and medically important fusaria. Fungal Genet Biol 52:20-31. https://doi.org/10.1016/j.fgb.2012.12.004 
41. O'Donnell K, Cigelnik E, Nirenberg HI (1998) Molecular systematics and phylogeography of the Gibberella fujikuroi species complex. Mycologia 90: 465-493. https://doi.org/10.1080/00275514.1998.12026933

42. Petkar A, Langston DB, Buck JW, et al (2017) Sensitivity of Fusarium oxysporum f. sp. niveum to prothioconazole and thiophanate-methyl and gene mutation conferring resistance to thiophanatemethyl. Plant Dis 101:366-371. https://doi.org/10.1094/PDIS-09-16-1236-RE

43. Pettersen EF, Goddard TD, Huang CC, et al (2004) UCSF Chimera - A visualization system for exploratory research and analysis. J Comput Chem 25:1605-1612. https://doi.org/10.1002/jcc.20084

44. Porollo AA, Adamczak R, Meller J (2004) POLYVIEW: A flexible visualization tool for structural and functional annotations of proteins. Bioinformatics 20:2460-2462. https://doi.org/10.1093/bioinformatics/bth248

45. Qiu JB, Xu JQ, Yu JJ, et al (2011) Localisation of the benzimidazole fungicide binding site of Gibberella zeae $\beta 2$-tubulin studied by site-directed mutagenesis. Pest Manag Sci 67:191-198. https://doi.org/10.1002/ps.2050

46. Richards KL, Anders KR, Nogales E, et al (2000) Structure-function relationships in yeast tubulins. Mol Biol Cell 11:1887-1903. https://doi.org/10.1091/mbc.11.5.1887

47. Richardson JS, Richardson DC (1988) Erratum: Amino acid preferences for specific locations at the ends of a helices (Science (1988) (1648)). Science (80- ) 242:1624. https://doi.org/10.1126/science.242.4886.1624-b

48. Richardson JS, Richardson DC (1989) Principles and Patterns of Protein Conformation. Predict Protein Struct Princ Protein Conform 1-98. https://doi.org/10.1007/978-1-4613-1571-1_1

49. Sanchez G (2013) Las instituciones de ciencia y tecnología en los procesos de aprendizaje de la producción agroalimentaria en Argentina. El Sist argentino innovación Inst Empres y redes El desafío la creación y apropiación Conoc 1025:1010-1025. https://doi.org/10.1002/prot

50. Schroers HJ, Samuels GJ, Zhang N, Short DP, Juba J, Geiser DM (2016) Epitypification of Fusisporium (Fusarium) solani and its assignment to a common phylogenetic species in the Fusarium solani species complex. Mycologia 108: 806-819

51. Sevastos A, Labrou NE, Flouri F, Malandrakis A (2017) Glutathione transferase-mediated benzimidazole-resistance in Fusarium graminearum. Pestic Biochem Physiol 141:23-28. https://doi.org/10.1016/j.pestbp.2016.11.002

52. Smith JA, Pease LG, Kopple KD (1980) Reverse turns in peptides and protein. Crit Rev Biochem Mol Biol 8:315-399. https://doi.org/10.3109/10409238009105470

53. Suga H, Nakajima T, Kageyama K, Hyakumachi M (2011) The genetic profile and molecular diagnosis of thiophanate-methyl resistant strains of Fusarium asiaticum in Japan. Fungal Biol 115:1244-1250. https://doi.org/10.1016/j.funbio.2011.08.009

54. Tamura K, Nei M (1993) Estimation of the number of nucleotide substitutions in the control region of mitochondrial DNA in humans and chimpanzees. Mol Biol Evol 10:512-526. 
https://doi.org/10.1093/oxfordjournals.molbev.a040023

55. Tarafder M, Islam R, Datta B (2019) Carbendazim sensitivity of Fusarium solani soil isolates. Indian Phytopathol 72:705-710. https://doi.org/10.1007/s42360-019-00151-8

56. Thompson JD, Higgins DG, Gibson TJ (1994) CLUSTAL W: Improving the sensitivity of progressive multiple sequence alignment through sequence weighting, position-specific gap penalties and weight matrix choice. Nucleic Acids Res 22:4673-4680. https://doi.org/10.1093/nar/22.22.4673

57. Vajda S, Yueh C, Beglov D, et al (2017) New additions to the ClusPro server motivated by CAPRI. Proteins Struct Funct Bioinforma 85:435-444. https://doi.org/10.1002/prot.25219

58. Vela-Corcía D, Romero D, De Vicente A, Pérez-García A (2018) Analysis of $\beta$-tubulin-carbendazim interaction reveals that binding site for $\mathrm{MBC}$ fungicides does not include residues involved in fungicide resistance. Sci Rep 8:1-12. https://doi.org/10.1038/s41598-018-25336-5

59. Víglaš J, Olejníková $P$ (2021) An update on $A B C$ transporters of filamentous fungi - from physiological substrates to xenobiotics. Microbiol. Res. 246: 126684 http://dx.doi.org/10.1016/j.micres.2020.126684

60. Wiederstein M, Sippl MJ (2007) ProSA-web: Interactive web service for the recognition of errors in three-dimensional structures of proteins. Nucleic Acids Res 35:407-410. https://doi.org/10.1093/nar/gkm290

61. Williams KA, Deber CM (1991) Proline Residues in Transmembrane Helices: Structural or Dynamic Role? Biochemistry 30:8919-8923. https://doi.org/10.1021/bi00101a001

62. Xu S, Wang J, Wang H, et al (2019) Molecular characterization of carbendazim resistance of Fusarium species complex that causes sugarcane pokkah boeng disease. BMC Genomics 20:1-14. https://doi.org/10.1186/s12864-019-5479-6

63. Yan K, Dickman MB (1996) Isolation of a $\beta$-tubulin gene from Fusarium moniliforme that confers cold-sensitive benomyl resistance. Appl Environ Microbiol 62:3053-3056. https://doi.org/10.1128/aem.62.8.3053-3056.1996

64. Yang Y, Li MX, Duan YB, et al (2018) A new point mutation in $\beta 2$-tubulin confers resistance to carbendazim in Fusarium asiaticum. Pestic Biochem Physiol 145:15-21. https://doi.org/10.1016/j.pestbp.2017.12.006

65. Zhang H, Brankovics B, van der Lee TAJ, et al (2016) A single-nucleotide-polymorphism-based genotyping assay for simultaneous detection of different carbendazim-resistant genotypes in the Fusarium graminearum species complex. PeerJ 2016:. https://doi.org/10.7717/peerj.2609

66. Zhao Z, Liu H, Luo Y, et al (2014) Molecular evolution and functional divergence of tubulin superfamily in the fungal tree of life. Sci Rep 4:1-13. https://doi.org/10.1038/srep06746

67. Zhou Y, Xu J, Zhu Y, et al (2016) Mechanism of action of the benzimidazole fungicide on Fusarium graminearum: Interfering with polymerization of monomeric tubulin but not polymerized microtubule. Phytopathology 106:807-813. https://doi.org/10.1094/PHYTO-08-15-0186-R

\section{Tables}


Table 1

$Z$ scores of individual component of QMEAN for $\beta$-tubulin protein model of $F$. solani

\begin{tabular}{|ll|}
\hline Scoring function term & Z-score \\
\hline C-beta interactions & 0.25 \\
\hline All-atom pairwise & 0.24 \\
\hline Solvation & 0.85 \\
\hline Torsion angle & -2.31 \\
\hline QMEAN4 score $=0.82$ & -1.85 \\
\hline
\end{tabular}

Table 2

Nucleotide (GDP) binding sites with calculated bond distance and bond angle 


\begin{tabular}{|c|c|c|c|c|c|c|}
\hline Bond Type & H-Donor & H-Acceptor & $\begin{array}{l}\text { Distance } \\
(\AA)\end{array}$ & $\begin{array}{l}\text { Angle } \\
\text { XDA }\end{array}$ & $\begin{array}{l}\text { Angle } \\
\text { DAY }\end{array}$ & Theta \\
\hline $\begin{array}{l}\text { Conventional } \\
\text { Hydrogen Bond }\end{array}$ & $\beta: G L N 11: N$ & GDP14:01B & 2.88164 & 6.067 & 118.021 & \\
\hline $\begin{array}{l}\text { Conventional } \\
\text { Hydrogen Bond }\end{array}$ & $\beta: C Y S 12: N$ & GDP14:02A & 2.81274 & 8.263 & 146.499 & \\
\hline $\begin{array}{l}\text { Conventional } \\
\text { Hydrogen Bond }\end{array}$ & $\beta: G L N 15: N E 2$ & GDP14:06 & 3.12362 & 51.361 & 135.514 & \\
\hline $\begin{array}{l}\text { Conventional } \\
\text { Hydrogen Bond }\end{array}$ & $\beta: S E R 138: 0 G$ & GDP14:02A & 2.91155 & 58.906 & 93.549 & \\
\hline $\begin{array}{l}\text { Conventional } \\
\text { Hydrogen Bond }\end{array}$ & $\beta: S E R 138: 0 G$ & GDP14:05' & 2.70812 & 111.374 & 99.188 & \\
\hline $\begin{array}{l}\text { Conventional } \\
\text { Hydrogen Bond }\end{array}$ & B:GLY142:N & GDP14:03B & 2.91525 & 43.167 & 127.701 & \\
\hline $\begin{array}{l}\text { Conventional } \\
\text { Hydrogen Bond }\end{array}$ & $\beta: T H R 143: N$ & GDP14:03B & 2.51272 & 21.687 & 137.13 & \\
\hline $\begin{array}{l}\text { Conventional } \\
\text { Hydrogen Bond }\end{array}$ & B:GLY144:N & GDP14:02B & 2.79906 & 18.253 & 121.661 & \\
\hline $\begin{array}{l}\text { Conventional } \\
\text { Hydrogen Bond }\end{array}$ & ß:ASN204:ND2 & GDP14:02' & 3.12522 & 54.321 & 120.505 & \\
\hline $\begin{array}{l}\text { Conventional } \\
\text { Hydrogen Bond }\end{array}$ & $\beta:$ TYR222:OH & GDP14:02' & 3.00163 & 42.302 & 72.907 & \\
\hline $\begin{array}{l}\text { Conventional } \\
\text { Hydrogen Bond }\end{array}$ & ß:ASN226:ND2 & GDP14:06 & 2.55275 & 8.679 & 123.253 & \\
\hline $\begin{array}{l}\text { Conventional } \\
\text { Hydrogen Bond }\end{array}$ & GDP14:N2 & B:ASN204:OD1 & 2.59664 & 15.55 & 131.126 & \\
\hline $\begin{array}{l}\text { Carbon Hydrogen } \\
\text { Bond }\end{array}$ & B:GLY10:CA & GDP14:02B & 3.46944 & 25.517 & 108.499 & \\
\hline $\begin{array}{l}\text { Carbon Hydrogen } \\
\text { Bond }\end{array}$ & $\beta: G L Y 141: C A$ & GDP14:03A & 3.29923 & 21.382 & 104.781 & \\
\hline $\begin{array}{l}\text { Carbon Hydrogen } \\
\text { Bond }\end{array}$ & $\beta: S E R 176: C B$ & GDP14:02' & 3.7051 & 10.179 & 13.992 & \\
\hline $\begin{array}{l}\text { Carbon Hydrogen } \\
\text { Bond }\end{array}$ & GDP14:C8 & GDP14:01A & 3.44282 & 13.234 & 104.329 & \\
\hline $\begin{array}{l}\text { Pi-Donor Hydrogen } \\
\text { Bond }\end{array}$ & B:CYS12:SG & GDP14 & 3.14745 & & & 28.863 \\
\hline $\begin{array}{l}\text { Pi-Donor Hydrogen } \\
\text { Bond;Pi-Sulfur }\end{array}$ & B:CYS12:SG & GDP14 & 2.84006 & & & 14.331 \\
\hline
\end{tabular}




\section{Table 3}

Hydrogen bonds formed in carbendazim (MBC) binding with $\beta$-tubulin with their calculated bond distance

\begin{tabular}{|c|c|c|c|c|}
\hline Category & Bond Type & Bond Donor & $\begin{array}{l}\text { Bond } \\
\text { Acceptor }\end{array}$ & $\begin{array}{l}\text { Bond Distance } \\
(\AA)\end{array}$ \\
\hline Electrostatic & Attractive Charge & B:ARG156:HZ2 & MBC:C1 & 4.12 \\
\hline Electrostatic & Attractive Charge & B:ARG156:HZ2 & MBC:C3 & 3.95 \\
\hline Electrostatic & Attractive Charge & $\beta: G L U 194: C A$ & MBC:C1 & 4.78 \\
\hline Electrostatic & Attractive Charge & $\beta: A S N 195: C A$ & MBC:C1 & 5.27 \\
\hline Electrostatic & Attractive Charge & ß:ASP197:CA & MBC:C3 & 4.46 \\
\hline Electrostatic & Attractive Charge & $\beta: P R 0261: C A$ & $\mathrm{MBC}: \mathrm{C} 1$ & 5.24 \\
\hline Electrostatic & Attractive Charge & $\beta: P R 0261: C A$ & MBC:C3 & 4.43 \\
\hline $\begin{array}{l}\text { Hydrogen } \\
\text { Bond }\end{array}$ & $\begin{array}{l}\text { Conventional Hydrogen } \\
\text { Bond }\end{array}$ & MBC:H18 & $\beta: P R 0261: 0$ & 2.23 \\
\hline $\begin{array}{l}\text { Hydrogen } \\
\text { Bond }\end{array}$ & Carbon Hydrogen Bond & MBC:H16 & ß:GLU194:0 & 2.62 \\
\hline $\begin{array}{l}\text { Hydrogen } \\
\text { Bond }\end{array}$ & Carbon Hydrogen Bond & MBC:H17 & ß:GLU194:0 & 2.65 \\
\hline Hydrophobic & Alkyl & $\beta: A L A 254$ & MBC & 3.92 \\
\hline
\end{tabular}

*MBC-the ligand and $\beta$ - the receptor protein

\section{Table 4}

Hydrogen bond forming $\mathrm{H}$-donor and $\mathrm{H}$-acceptor amino acid residues with their positions in polypeptide chain and calculated bond-distance and bond-angle in protein-protein docking of $a$ - and $\beta$-tubulin proteins. 


\begin{tabular}{|c|c|c|c|c|c|c|}
\hline Category & Bond Types & H-Donor & H-Acceptor & $\begin{array}{l}\text { Distance } \\
(\AA)\end{array}$ & $\begin{array}{l}\text { Angle } \\
\text { XDA }\end{array}$ & $\begin{array}{l}\text { Angle } \\
\text { DAY }\end{array}$ \\
\hline $\begin{array}{l}\text { Hydrogen } \\
\text { Bond; }\end{array}$ & Salt Bridge & $\beta: A R G 162: N H 1$ & a:ASP98:OD2 & 2.58503 & 138.62 & 143.67 \\
\hline \multicolumn{7}{|c|}{ Electrostatic } \\
\hline $\begin{array}{l}\text { Hydrogen } \\
\text { Bond; }\end{array}$ & Salt Bridge & $\beta: L Y S 252: N Z$ & a:GLU71:OE1 & 3.75977 & 111.05 & 98.26 \\
\hline \multicolumn{7}{|c|}{ Electrostatic } \\
\hline $\begin{array}{l}\text { Hydrogen } \\
\text { Bond; }\end{array}$ & Salt Bridge & B:ARG331:NH1 & a:GLU207:OE2 & 3.81886 & 139.54 & 145.41 \\
\hline \multicolumn{7}{|c|}{ Electrostatic } \\
\hline $\begin{array}{l}\text { Hydrogen } \\
\text { Bond; }\end{array}$ & Salt Bridge & a:LYS96:NZ & ß:ASP128:OD1 & 3.05739 & 104.57 & 92.99 \\
\hline \multicolumn{7}{|c|}{ Electrostatic } \\
\hline $\begin{array}{l}\text { Hydrogen } \\
\text { Bond }\end{array}$ & $\begin{array}{l}\text { Conventional } \\
\text { Hydrogen Bond }\end{array}$ & $\beta: C Y S 129: S G$ & a:LYS96:0 & 3.75908 & 98.55 & 103.54 \\
\hline $\begin{array}{l}\text { Hydrogen } \\
\text { Bond }\end{array}$ & $\begin{array}{l}\text { Conventional } \\
\text { Hydrogen Bond }\end{array}$ & $\beta: A S N 347: N D 2$ & a:PR0175:0 & 1.89782 & 124.85 & 173.65 \\
\hline $\begin{array}{l}\text { Hydrogen } \\
\text { Bond }\end{array}$ & $\begin{array}{l}\text { Conventional } \\
\text { Hydrogen Bond }\end{array}$ & $\beta: G L N 350: N E 2$ & a:THR179:0 & 3.08042 & 93.34 & 140.43 \\
\hline $\begin{array}{l}\text { Hydrogen } \\
\text { Bond }\end{array}$ & $\begin{array}{l}\text { Conventional } \\
\text { Hydrogen Bond }\end{array}$ & a:LYS401:NZ & $\beta: G L Y 429: 0$ & 3.09468 & 98.12 & 107.38 \\
\hline $\begin{array}{l}\text { Hydrogen } \\
\text { Bond }\end{array}$ & $\begin{array}{l}\text { Conventional } \\
\text { Hydrogen Bond }\end{array}$ & a:ARG402:NH2 & $\beta: G L Y 429: 0$ & 1.87444 & 119.31 & 138.60 \\
\hline $\begin{array}{l}\text { Hydrogen } \\
\text { Bond }\end{array}$ & $\begin{array}{l}\text { Carbon } \\
\text { Hydrogen Bond }\end{array}$ & a:SER178:CA & $\beta: G L N 350: 0 E 1$ & 2.69845 & 100.73 & 110.04 \\
\hline $\begin{array}{l}\text { Hydrogen } \\
\text { Bond }\end{array}$ & $\begin{array}{l}\text { Carbon } \\
\text { Hydrogen Bond }\end{array}$ & a:THR179:CA & $\beta: A S N 256: O D 1$ & 2.42814 & 96.09 & 118.38 \\
\hline
\end{tabular}

\section{Figures}

\section{Figure 1}

Maximum-likelihood phylogenetic tree of Fusarium solani species complex (FSSC) inferred from ITS nucleotide dataset rooted on that of $F$. staphyleae. Accession number of each sequence is given in 
parenthesis. Values in the nodes indicate bootstrap support. Our F. solani isolates are marked as red.

\section{Figure 2}

Maximum-likelihood phylogenetic tree of Fusarium species inferred from $\beta$-tubulin nucleotide dataset rooted on that of Epichloe festucae. Accession number of each sequence is given in parenthesis. Values in the nodes indicate bootstrap support. Different colours are represented by different species complexes which are abbreviated as FSaSC (Fusarium sambucinum species complex), FIESC (Fusarium incarnatumequiseti species complex), FTSC (Fusarium tricinctum species complex), FHSC (Fusarium heterosporum species complex), FFSC (Fusarium fujikuroi species complex), FOSC (Fusarium oxysporum species complex), FSSC (Fusarium solani species complex) and FDSC (Fusarium decemcellulare species complex).

\section{Figure 3}

A. Organization of $\beta$-tubulin gene of Fusarium solani. The downward vertical arrow shows the initiator and terminator nucleotide number of each exon. The grey regions represent exon and the line drawings represent intron regions. The diagram is drawn to scale, with nucleotide length measured in base pair (bp). B. Comparison of complete $\beta$-tubulin gene of different Fusarium species. The species are arranged alphabetically in ascending order. The positions exon and intron are marked as dark and light, respectively; their lengths are given in bp. Total nucleotide length (bp) of each gene is shown at the end.

\section{Figure 4}

Alignment of translated amino acid sequence of $\beta$-tubulin of Fusarium solani with other Fusarium species. A. comparison of amino acid from 1-300. B. comparison of amino acid from 301-446. The matching residues are represented in dots. Abbreviation of species and the sequence accession numbers are given at the end.

\section{Figure 5}


Predicted secondary structures of $F$. solani (A) and F. oxysporum f.sp. cubense (B). The red, green and blue coloured regions are $\alpha$-helix, $\beta$-strand and coil, respectively. The hydrophobicity levels of different amino acid residues like relative solvent accessibility (RSA) values are represented in 0 to 10 scales; where, 0 value represents completely buried i.e. 0-9\% RSA (Black) and the value 9 represents fully exposed i.e. 90-100\% RSA (White).

\section{Figure 6}

Structural justification of the $\beta$-tubulin model. A. ProSA overall Z score (-10.11) is indicated in the graph as black dot, marked with red circle. A negative value of overall energy profile confirmed the consistent structural conformation of $\beta$-tubulin. B. Energy profile of the $\beta$-tubulin homology model. C. QMEAN4 score 0.82 marked with red star. D. Ramachandran plot of the $\beta$-tubulin model showing $97.436 \%$ of amino acid residues in the core region.

\section{Figure 7}

Homology model of tertiary structure of $F$. solani $\beta$-tubulin showing nucleotide binding, carbendazim binding, and a-tubulin binding domains. A. Space-filling model showing nucleotide binding domain with bound GDP-14. B. Enlarged view of A, the GDP-14 binding domain of $F$. solaniSF0301 $\beta$-tubulin with amino acid residues hydrogen-bonded with GDP-14 (Blue). The conventional hydrogen bonds are marked as green and non-conventional carbon-hydrogen bonds as grey. C. Ribbon model showing carbendazim binding domains $\mathbf{D}$. Enlarged view of $\mathrm{C}$, showing putative carbendazim binding pocket of $\beta$-tubulin with conventional hydrogen bonds marked as green, charged electrostatic interactions marked as brown, nonconventional carbon hydrogen bonds marked as black, alkyl hydrophobic interaction marked as magenta. E. $\alpha / \beta$-tubulin hetero-dimer with their interactions between them with calculated bond distance and interacting amino acid residue. $\alpha$-tubulin is purple and $\beta$-tubulin is cyan in colour.

\section{Figure 8}

Homology model of tertiary structure of $F$. solani $\beta$-tubulin showing nucleotide binding, carbendazim binding, and $\alpha$-tubulin binding domains. A. Space-filling model showing nucleotide binding domain with 
bound GDP-14. B. Enlarged view of A, the GDP-14 binding domain of $F$. solani SF0301 $\beta$-tubulin with amino acid residues hydrogen-bonded with GDP-14 (Blue). The conventional hydrogen bonds are marked as green and non-conventional carbon-hydrogen bonds as grey. C. Ribbon model showing carbendazim binding domains $\mathbf{D}$. Enlarged view of $C$, showing putative carbendazim binding pocket of $\beta$-tubulin with conventional hydrogen bonds marked as green, charged electrostatic interactions marked as brown, nonconventional carbon hydrogen bonds marked as black, alkyl hydrophobic interaction marked as magenta. E. $\alpha / \beta$-tubulin hetero-dimer with their interactions between them with calculated bond distance and interacting amino acid residue. $\alpha$-tubulin is purple and $\beta$-tubulin is cyan in colour. 